\title{
Chapter 7 \\ The Urban Corridor of Venice and The Case of Padua
}

\author{
Marco Noro, Renato Lazzarin, and Filippo Busato
}

\begin{abstract}
Urban Heat Island effect was widely studied in large cities around the world, more rarely in medium size ones. The chapter reports on the study of the UHI phenomenon in Padua, a medium size city of the North-East of Italy, one of the most industrialized and developed parts of the country. Experimental measurements were carried out during 2012 summer, recording the main thermo-hygrometric variables (dry-bulb temperature, relative humidity, global solar radiation) by a mobile survey along an exact path crossing different zones of the city area: urban, sub-urban and rural. The analysis of the data highlights the presence of UHI effect with different magnitudes in function of the zone of the city. In the city centre, an historical zone, the effect was up to $7^{\circ} \mathrm{C}$. In the meantime, some measurements in situ were carried out in order to evaluate other thermal comfort indexes rather than air temperature and humidity only: wind velocity and mean radiant temperature (besides the other meteorological variables) in some characteristic sites of the city area like historic centre, high and low density populated residential zones, industrial zone, rural zone, were recorded. In particular, a very famous square of the city (Prato della Valle) was analysed: it can be considered representative of the phenomenon because of the size and the very different characteristics from the UHI effect point of view. RayMan simulation model was used to calculate some outdoor comfort indexes and Envimet model was further used to evaluate the effect of some mitigation strategies in characteristic sites of the city.
\end{abstract}

Keywords Urban heat island • Padua • RayMan • ENVImet • Outdoor thermal comfort

M. Noro $(\bowtie) \bullet$ R. Lazzarin $\bullet$ F. Busato

Department of Management and Engineering (DTG), University of Padova,

Stradella San Nicola 3 - 36100, Vicenza (VI), Italy

e-mail: marco.noro@unipd.it 


\subsection{Urban and Environmental Framework}

Veneto Region climate is characterized by different issues: the region is between $44.9^{\circ}$ and $46.7^{\circ}$ North latitude and it is between central Europe (where western and Atlantic currents are predominant) and southern Europe (where subtropical anticyclones and Mediterranean Sea influences are predominant). The presence of the Po Valley, the Adriatic Sea, the Alpi Mountains and the Garda Lake are further factors that affect the Veneto Region climate. In a simple way, the climate is characterized by two main regions: the alpine zone (central Europe mountain climate) and the Po Valley zone (continental climate), with two sub-regions with milder climate (Garda Lake and Adriatic Sea zones).

Padua stands on the Bacchiglione River, $40 \mathrm{~km}$ West of Venice and $29 \mathrm{~km}$ SouthEast of Vicenza, inside the eastern part of the Po Valley; it has a humid subtropical climate (Köppen climate classification $\mathrm{Cfa}$ ) with cold winters and hot summers, frequently associated with air stagnation (respectively fog and sultriness). The city has an area of $93 \mathrm{~km}^{2}$, a mean altitude of $12 \mathrm{~m}$ a.s.1. and a population of 214,000 (as of 2011); the population density is quite high for Italy, 2300 inhabitants $/ \mathrm{km}^{2}$, the higher in Veneto Region and not far from that of Rome. The city is picturesque, with a dense network of arcaded streets opening into large municipal squares ("piazze"), and many bridges crossing the various branches of the Bacchiglione River, which once surrounded the ancient walls like a moat. The industrial area of Padua was created in 1946, in the eastern part of the city; now it is one of the biggest industrial zones in Europe, having an area of 11 million $\mathrm{m}^{2}$. Here the main offices of 1300 industries employing 50,000 people are located. It can be of some interest to give some feature (data of 2010 (ARPAV 2011)) concerning the situation of the energy consumption of the territory. In terms of subdivision in electricity, thermal and transport consumption, no data at Province level are available. On the regional level, the respective values are: 2724, 6042 and $3088 \mathrm{ktep}$. The Province of Padua consumes $5500 \mathrm{GWh}$ of electricity (19\% on the Veneto Region basis, $1.8 \%$ on Italy basis), a half is consumed by industry sector and $28 \%$ by tertiary sector. Concerning the residential sector only, Padua city per-capita consumption of electricity is 1300 $\mathrm{kWh}_{\text {year }}{ }^{-1}$ while the consumption of natural gas is around $700 \mathrm{~m}^{3}$ year $^{-1}$ (the averages of all Italian capitals of province are respectively $1200 \mathrm{kWh}_{\text {year }}{ }^{-1}$ and $390 \mathrm{~m}^{3}$ year $^{-1}$, data 2011 (ISTAT 2012)).

City of Padua is quite sensitive to initiatives concerning the protection of the environment, human health and energy saving. During the last decade, the Municipality has been involved in different European Projects (Life Siam - n. LIFE04 ENV/IT/000524, Life "South-EU Urban ENVIPLANS”, Belief - Building in Europe local intelligent energy forums, LIFE-PARFUM); initiatives like the arrangement of the Energy Plan and the Climate Plan have been adopted in order to give practical tools to reduce energy consumption and to introduce adaptation and mitigation strategies to climate change.

All these climatic and environmental characteristics of the territory can put forward the interest in the study of the heat island effect of the city of Padua. 


\subsection{Pilot Areas Identification Methodology}

The first phase of the study was carried out by choosing five areas of interest within the city of Padua, in which to make the analysis of urban planning and surveys on urban heat island. Such areas were selected on the basis of the location with respect to a transect north-west to south-east (Fig. 7.1) and compared to urban characteristics: historic centre, urban mixed, high density residential, low-density residential, industrial. The selection of the pilot area, between the five hypothesis, were done considering useful to study the typical settlement of the central Veneto Region, with the aim to replicate in other areas the results and the mitigation techniques studied.

\subsection{UHI Phenomena in the Pilot Area}

\subsubsection{Mobile Surveys}

The goal of the field survey was a first characterization the UHI phenomenon in a medium size city like Padua (Noro et al. 2015). Within the framework of the "UHI" Project the Authors used mobile surveys with the measurement instrumentation installed on a vehicle running through the territory from the rural to the urban zone, in order to log data continuously (Fig. 7.1).

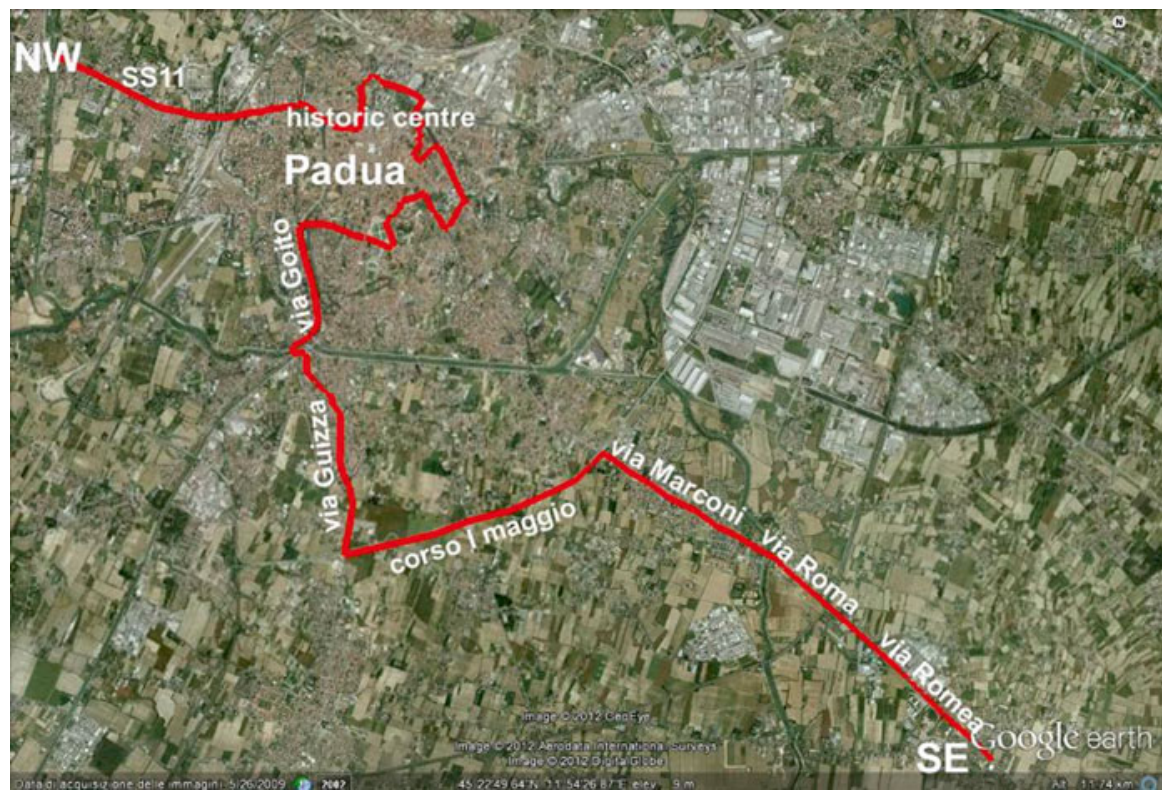

Fig. 7.1 The path along which the mobile surveys were conducted, going from the NW to the SE of Padua and return (Google Earth) 


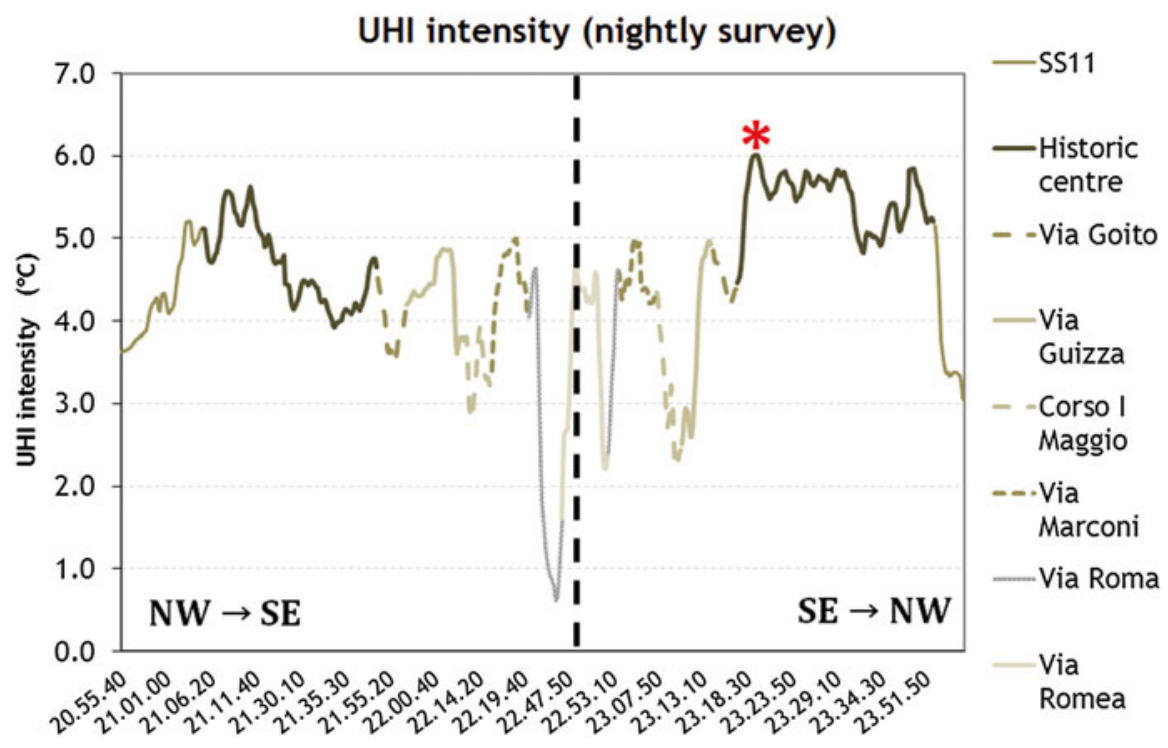

Fig. 7.2 UHI intensity during night-time mobile survey of the 30th July, 2012. The vertical broken line indicates the U-turn during the survey (the names of the streets refer to Fig. 7.1). The red star represents Prato della Valle

Experimental data were logged by mobile surveys from 26 July 2012 to 9 August 2012, some of them in double sessions: day-time (during late afternoon) and night-time session (between 1 and $4 \mathrm{~h}$ after the sunset in order to investigate the phenomenon during its potentially maximum intensity). Dry-bulb air temperature, relative humidity and solar global radiation on the horizontal, with a time step of $5 \mathrm{~s}$, were the main variables measured by the mobile station equipped on a vehicle. UHI intensity was determined by the difference between mobile measured air temperature and the value recorded at the same time by the reference ARPAV (Regional Agency for Environment Protection in Veneto) rural fixed meteorological station of Legnaro (rural zone, $8.5 \mathrm{~km}$ far from the city centre).

Details about the path, the instrumentation used and the measurement procedure are available in references (Noro et al. 2015). Here some very brief results are reported. Concerning air temperature, urban heat island intensity would be mostly present during night-time in the range of $3-6^{\circ} \mathrm{C}$, while the day-time would show a much less significant effect $\left(1.2-2{ }^{\circ} \mathrm{C}\right.$, Fig. 7.2$)$. Only the "return" (SE to $\mathrm{NW}$ ) path was considered for the UHI intensity measurement because this was the most precautionary path, both in spatial terms -moving from the countryside towards the city centre - and in temporal terms - as the air was cooling. Considering the night-time surveys, the minimum UHI intensity was recorded in a lateral street (an unpaved dirt patch road in the countryside) of via Roma ("via" means street in Italian), crossed only during the NW to SE path. The maximum UHI intensity was 


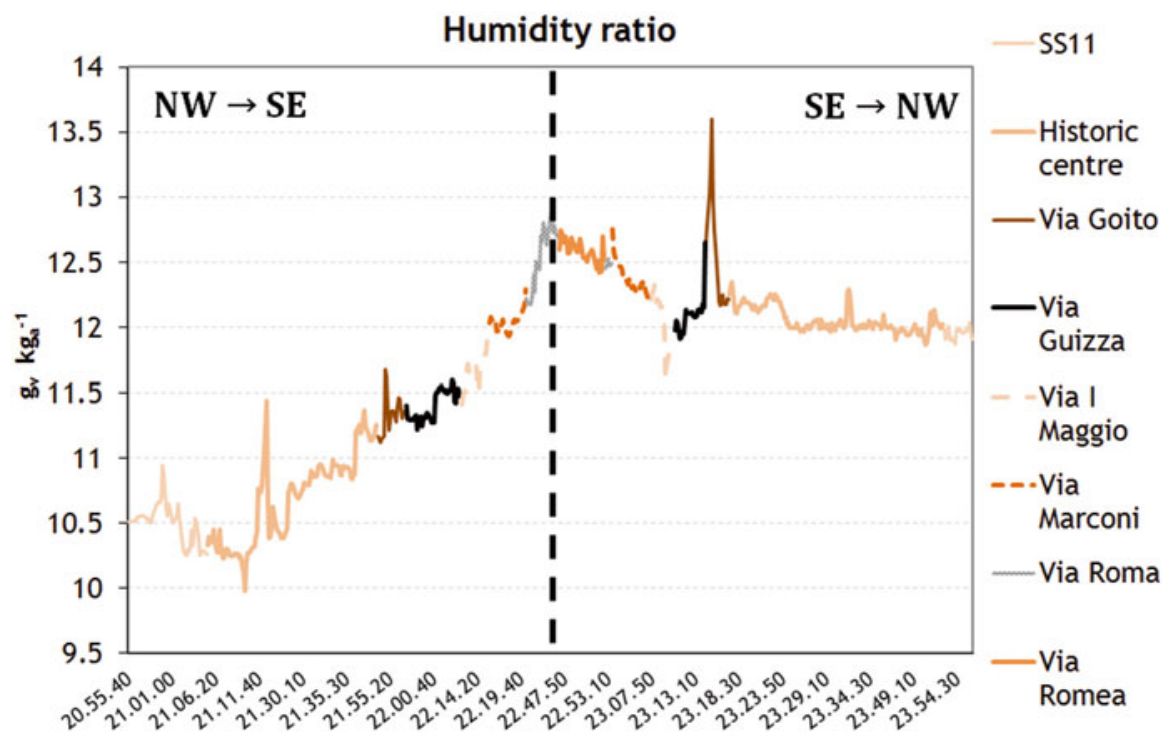

Fig. 7.3 Humidity ratio during the night-time mobile survey of the 30th July, 2012. The vertical broken line indicates the U-turn during the survey (the names of the streets refer to Fig. 7.1)

recorded across the narrow streets (high $\mathrm{H} / \mathrm{W}$ ratio) of the historic centre. As depicted in Fig. 7.2, going along via Guizza (a long road that traverse the sub-urban to inside of the city) UHI intensity would always increase, mainly due to the increase of the $\mathrm{H} / \mathrm{W}$ ratio and the increase of the vertical and horizontal impervious surfaces facing the road. The subsequent stretch of path (via Goito) was along San Gregorio Canal, so the evaporative cooling effect of water would lead to a decrease of the temperature.

The graphs concerning humidity ratio (more significant with respect to relative humidity because it is independent on air temperature) show some particular situation along the path, with a presence of water and/or green areas, but the presence of a gradient directed from the countryside to the city centre (from 12.8 to $12 \mathrm{~g}_{\mathrm{v}} \mathrm{kg}_{\mathrm{a}}{ }^{-1}$ in Fig. 7.3) is apparent. Differences in humidity ratio between rural and urban zones are more noticeable during the daily runs because of the higher evapotranspiration effect due to the presence of the solar radiation.

Prato della Valle, in the centre of the city, is a very famous and picturesque circle and the second largest (about $90,000 \mathrm{~m}^{2}$ ) urban square in Europe (the first being the Red Square of Moscow), with a lot of water flows and green zones, so a decrease in nightly temperature would be expected, while a maximum shown as the red star in the historic centre in Fig. 7.2 was measured. As a matter of fact the path passes along the perimeter and not inside the circle: the spatial influence of the green would be limited and a deeper investigation within this zone will be presented in the next section. 
Table 7.1 Comparison between the three outdoor comfort indexes. Values between brackets in PMV column refer to the correspondent values of the other indexes

\begin{tabular}{l|l|l|l}
\hline PMV & PET $\left({ }^{\circ} \mathrm{C}\right)$ & SET $^{*}\left({ }^{\circ} \mathrm{C}\right)$ & Sensation \\
\hline$>3(3.5)$ & 41 & $>37.5$ & Very hot, great discomfort \\
\hline $2-3(2.5)$ & 35 & $34.5-37.5$ & Hot, very unaccepTab. \\
\hline $1-2(1.5)$ & 29 & $30-34.5$ & Warm, uncomforTab., unaccepTab. \\
\hline $0.5-1(0.5)$ & 23 & $25.6-30$ & Slightly warm, slightly unaccepTab. \\
\hline$-0.5-0.5$ & & $22.2-25.6$ & ComforTab., accepTab. \\
\hline$-1--0.5(-0.5)$ & 18 & $17.5-22.2$ & Slightly cool, slightly unaccepTab. \\
\hline$-2--1(-1.5)$ & 13 & $14.5-17.5$ & Cool, unaccepTab. \\
\hline$-3--2(-2.5)$ & 8 & $10-14.5$ & Cold, very unaccepTab. \\
\hline$<-3(-3.5)$ & 4 & $<10$ & Very cold, great discomfort \\
\hline
\end{tabular}

\subsubsection{In Situ Measurements}

Besides the mobile surveys, in situ measurements were performed in some characteristic sites of the city area along the path, in order to measure air temperature and humidity, wind velocity and mean radiant temperature. Consequently these data were processed using the RayMan model (Matzarakis et al. 2007, 2010) in order to calculate some outdoor thermal comfort indexes: the Predicted Mean Vote (PMV), the Physiological Equivalent Temperature (PET) and the new Standard Effective Temperature (SET*). RayMan model is a simulation tool for the estimation of radiation fluxes and mean radiant temperature $\left(T_{m r}\right)$ and other variables, compatible with Windows $\AA$ that can analyse complex urban structures and other environments. The model requires only basic meteorological data (air temperature, air humidity and wind speed) for the simulation of radiation flux densities and common thermal indices for the thermal human-bioclimate.

Table 7.1 reports a comparison of the three thermal comfort index values. All these indexes were calculated by the mean radiant temperature $T_{m r}$, a physical quantity that accounts for the human-biometeorological influence of short - and long wave radiation flux densities (Jendritzky and Nubler 1981). While PET and SET* have been specifically defined to assess outdoor thermal comfort (Matzarakis et al. 2007, 2010); (Mayer 1993); (Gagge et al. 1986); (Höppe 1999); (Mayer and Höppe 1987), the use of PMV is not universally recognized. Also the ISO 7730 standard focused on the use of PMV only as indoor thermal comfort index. Nevertheless some authors applied the use of PMV to outdoor environment (Matzarakis et al. 2007, 2010); (Berkovic et al. 2012); (Honjo 2009); (Jendritzky and Nubler 1981); (Thorsson et al. 2004). In this study the mean radiant temperature was measured using the globothermometer during night-time measurements only, when UHI intensity was higher. For this reason the use of PMV for outdoor thermal comfort assessment was judged to be suiTab. for this study.

Table 7.2, 7.3, 7.4, 7.5, and 7.6 provide the description of the five sites selected for the in situ measurements, representative of very different zones of the fabric of 
Table 7.2 Data obtained in measurement sessions in via Rinaldi (historic centre) (see also Fig. 7.1). The " $X$ " refer to the point of measurement. Thermal comfort indexes refer to a person with summer clothing ( 0.5 clo) and slight activity level ( $80 \mathrm{~W}$ above the basal metabolism) (Google Earth-RayMan)

\begin{tabular}{l|l|l|l|l}
\hline Via Rinaldi (H/W=1.8 - $\mathrm{SVF}=0.18)$ \\
\hline
\end{tabular}

the city. The pictures show the main uses of territory, all the data measured during experimental sessions were reported in the Tab.s; the sites differ for the decreasing $\mathrm{H} / \mathrm{W}$ ratio (height of buildings to width of street) and for the increasing SVF (sky view factor).

Via Rinaldi is an urban canyon in the historic centre of the city (Table 7.2). Street pavement was constructed by porphyry, buildings by brick walls and tiled roofs; no trees are present. It is characterized by a relative high $\mathrm{H} / \mathrm{W}$ ratio (street width $5.5 \mathrm{~m}$, buildings height between 8 and $12 \mathrm{~m}$ ) and a small SVF (calculated by the RayMan model by position and height of buildings). The latter hampers the nightly cooling of surfaces causing the mean radiant temperatures to be higher or similar to air temperatures (respectively around $29^{\circ} \mathrm{C}$ and between 28 and $29^{\circ} \mathrm{C}$ ). UHI intensity was always more than $4{ }^{\circ} \mathrm{C}$ during the measurement sessions. Such environmental 
Table 7.3 Data obtained in measurement sessions in via Pindemonte (see also Fig. 7.1). The " $X$ " refer to the point of measurement. Thermal comfort indexes refer to a person with summer clothing ( $0.5 \mathrm{clo}$ ) and slight activity level ( $80 \mathrm{~W}$ above the basal metabolism) (Google Earth-RayMan)

\begin{tabular}{|l|l|l|}
\hline Via Pindemonte $(\mathrm{H} / \mathrm{W}=1.2-\mathrm{SVF}=0.29)$ \\
\hline
\end{tabular}

conditions determines, for a person with summer clothing $(0.5$ clo $)$ and slight level of activity (metabolic rate $80 \mathrm{~W}$ ), slight thermal stress (PMV and PET) or thermal comfort (SET*). During day-time UHI intensity was small, about $0.4-0.8^{\circ} \mathrm{C}$. Lower values of UHI could be measured during the morning because direct solar radiation would reach the point of measurement only during central hours of the day (Table 7.2).

Two residential zones were studied: via Pindemonte (higher population density) (Table 7.3) and via San Basilio (lower population density) (Table 7.4). The first is a lateral street of via Guizza (Fig. 7.1) with high apartment buildings (18 m) and wide street (15 m) so H/W is lower (1.2) than that of via Rinaldi. The pavement is covered with asphalt and there is the presence of trees (Table 7.3). The SVF measured was slightly higher than via Rinaldi but mean radiant temperature values were near to dry-bulb air temperatures, respectively 28 and $27.2-27.7^{\circ} \mathrm{C}$. The lower values of 
Table 7.4 Data obtained in measurement sessions in via San Basilio (see also Fig. 7.1). The " $X$ " refer to the point of measurement. Thermal comfort indexes refer to a person with summer clothing ( $0.5 \mathrm{clo}$ ) and slight activity level ( $80 \mathrm{~W}$ above the basal metabolism) (Google Earth-RayMan)

\begin{tabular}{|l|l|l|}
\hline Via San Basilio $(\mathrm{H} / \mathrm{W}=0.4-\mathrm{SVF}=0.75)$ \\
\hline
\end{tabular}

$T_{m r}$ and the higher values of wind velocity in via Pindemonte with respect to via Rinaldi resulted in lower values of the thermal comfort indexes.

Via San Basilio (Table 7.4) is mainly characterized by detached houses with height of $6-8 \mathrm{~m}$ and streets width of $18 \mathrm{~m}$, so the $\mathrm{H} / \mathrm{W}$ ratio is quite small $(0.4)$. The lack of trees is also the reason of high SVF value (0.75). This is why the mean radiant temperature measured was always $0.5-1{ }^{\circ} \mathrm{C}$ lower than air temperature, so PMV and PET indicate full thermal comfort situation; nevertheless UHI intensity measured during evening sessions was quite significant, about $3-5{ }^{\circ} \mathrm{C}$. During the day no significant UHI effect measured.

In order to compare environmental conditions of urban and sub-urban sites with a rural site, measurements in a lateral unpaved road of via Roma were carried out (Table 7.5, Fig. 7.1). The road winds through agricultural fields with no obstacles nearby $(\mathrm{SVF}=1)$; mean radiant temperature was $2-3{ }^{\circ} \mathrm{C}$ lower than air temperature, due to the very high SVF and the lower temperature of the agricultural surface (characterized by higher emissivity, lower thermal inertia and higher water storage capacity with respect to urban surfaces). 
Table 7.5 Data obtained in measurement sessions in a lateral dirt road of via Roma (see also Fig. 7.1). The " $X$ " refer to the point of measurement. Thermal comfort indexes refer to a person with summer clothing $(0.5$ clo) and slight activity level ( $80 \mathrm{~W}$ above the basal metabolism) (Google Earth)

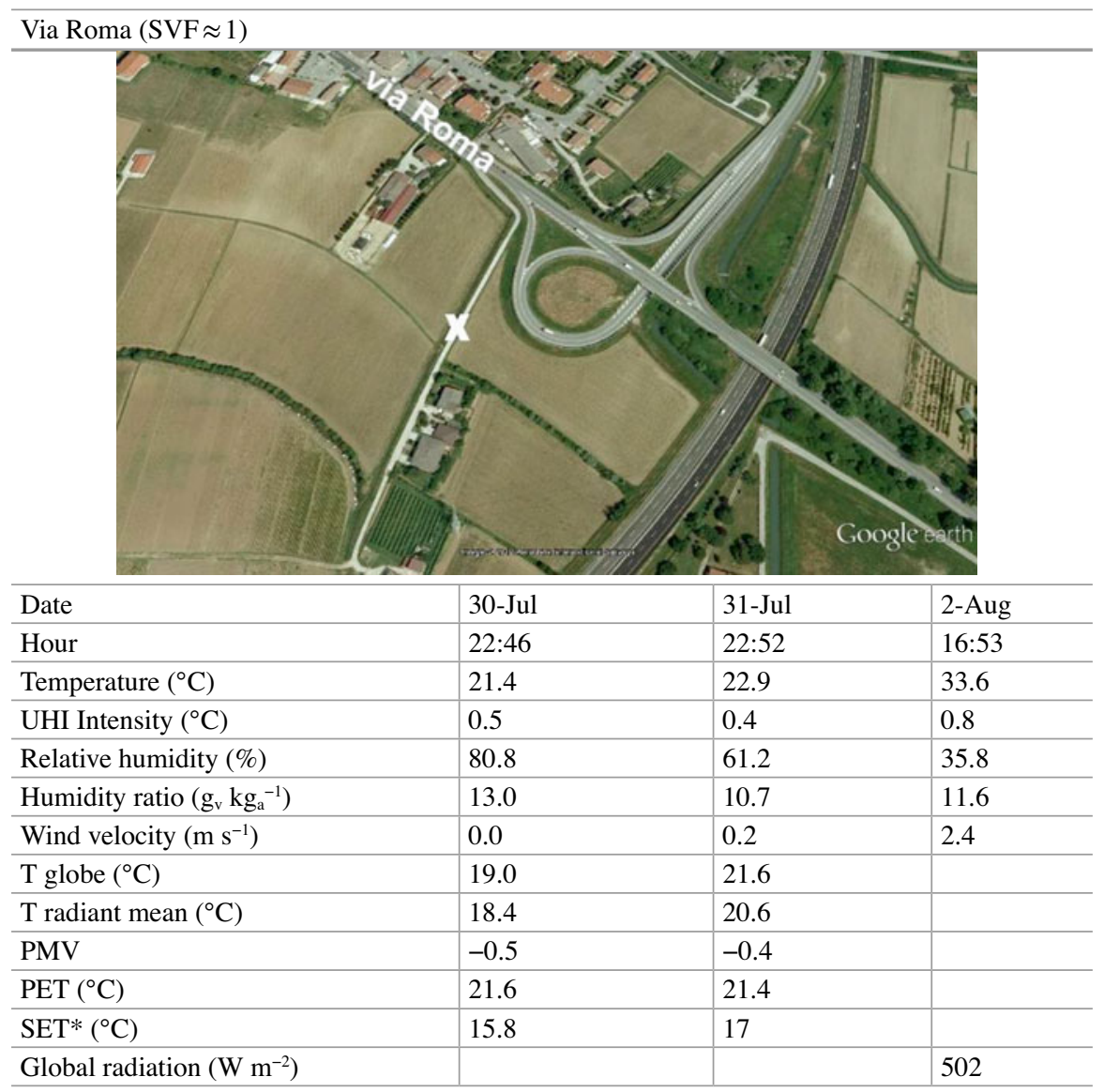

Finally, a deeper analysis of the thermal comfort in Prato della Valle was performed. This very popular circle is characterized by a central green island delineated by a channel decorated by statues and encircled by a wide asphalt circle road (Table 7.6). Because of the extension of the square, six different positions were fixed for the measurements.

The results indicate a difference of $0.5-1{ }^{\circ} \mathrm{C}$ in the air temperature between position 4 (on the green) and external positions near urban streets $(1,2,3,6$ ); a quite larger difference in mean radiant temperature was measured, with a maximum of $7^{\circ} \mathrm{C}$, because of the different surface characteristics (emissivity, thermal inertia and water storage capacity) and SVF (higher) at the centre of the square with respect to outer positions. 
Table 7.6 Data obtained in measurement sessions in Prato della Valle (dimension of ellipse are $180 \times 230 \mathrm{~m})($ see also Fig. 7.1). Thermal comfort indexes refer to a person with summer clothing ( 0.5 clo) and slight activity level ( $80 \mathrm{~W}$ above the basal metabolism) (Google Earth)

\begin{tabular}{|c|c|c|c|c|c|c|}
\hline \multicolumn{7}{|l|}{ Prato della Valle } \\
\hline \\
\hline & Pos.1 & Pos.2 & Pos.3 & Pos.4 & Pos.5 & Pos.6 \\
\hline Date & 2-Aug & 2-Aug & 2-Aug & 2-Aug & 2-Aug & 2-Aug \\
\hline Hour & $21: 53$ & $22: 03$ & $22: 14$ & $22: 25$ & $22: 35$ & $22: 44$ \\
\hline Temperature $\left({ }^{\circ} \mathrm{C}\right)$ & 28.4 & 28.4 & 28.1 & 27.0 & 26.9 & 27.4 \\
\hline UHI Intensity $\left({ }^{\circ} \mathrm{C}\right)$ & 3.2 & 3.9 & 4.3 & 3.8 & 3.7 & 4.7 \\
\hline Relative humidity (\%) & 48.0 & 48.2 & 49.1 & 52.9 & 53.5 & 51.5 \\
\hline Humidity ratio $\left(\mathrm{g}_{\mathrm{v}} \mathrm{kg}_{\mathrm{a}}{ }^{-1}\right)$ & 11.6 & 11.7 & 11.7 & 11.8 & 11.8 & 11.7 \\
\hline Wind velocity $\left(\mathrm{m} \mathrm{s}^{-1}\right)$ & 0.8 & 0.8 & 0.8 & 0.8 & 0.7 & 0.7 \\
\hline T globe $\left({ }^{\circ} \mathrm{C}\right)$ & 27.8 & 28.1 & 27.2 & 24.8 & 25.3 & 26.5 \\
\hline T radiant mean $\left({ }^{\circ} \mathrm{C}\right)$ & 26.5 & 27.4 & 25.2 & 20.1 & 22.2 & 24.8 \\
\hline PMV & 0.8 & 0.8 & 0.6 & 0.0 & 0.1 & 0.5 \\
\hline $\operatorname{PET}\left({ }^{\circ} \mathrm{C}\right)$ & 26.1 & 26.5 & 25.3 & 22.5 & 23.3 & 24.7 \\
\hline $\mathrm{SET}^{*}\left({ }^{\circ} \mathrm{C}\right)$ & 20.1 & 20.5 & 19.3 & 16.5 & 17.6 & 19.0 \\
\hline
\end{tabular}

The thermal comfort indexes calculation had reflected these considerations: PMV and PET had indicated a slightly warm environment at outer positions while on the green there was a neutral situation.

It is interesting to compare Pos. 4 and 5: the first was on the grass, the second was on a dirt patch near a fountain. Even so, same air temperature $\left(27^{\circ} \mathrm{C}\right)$ was measured at these locations. This was mainly due to the lower $T_{m r}$ for Pos. 4 and to the evaporative cooling effect for Pos. 5 . 


\subsection{Feasibility Study: UHI Mitigation Strategies by Simulations}

Many mitigation measures can be adopted and have been proposed by various researchers, which could be classified as measures that could only be implemented during the design and planning stage (eg sky view factor and building material etc.) and those that could also be implemented after the design and planning stages (eg green areas and roof spray cooling) (Rizwan et al. 2008). RayMan model was used in order to quantify possible increasing in thermal comfort as a consequence of some possible mitigating measures of both types. Main inputs of the model relate to the outdoor environment conditions: dry-bulb air temperature and RH, wind velocity, Bowen ratio (ratio of sensible over latent heat flux in evapotranspiration, fixed at 1.5) and cloud cover (fixed at 1 okta). Other inputs are the albedo and emissivity of surfaces, fixed respectively at 0.30 and 0.95 , typical values of urban environment.

The following limitations in RayMan analysis must be highlighted:

- emissivity is considered the same for all the different kinds of surfaces;

- consequences of higher albedos cannot be correctly evaluated: the lower surfaces temperature would not be estimated as it is given by the air temperature (input of the software).

For these reasons next simulations concern topology modifications only (height and distance of buildings, presence of green); obviously these are mitigation strategies that can be implemented during the design and planning stage only.

As described by Noro et al. (2015) and Busato et al. (2014), a slightly warm PMV was obtained for via Rinaldi (Padua old town) and in via Pindemonte, the pilot area (high density population residential zone): for the latter the modification in thermal comfort with some characteristics of the site was evaluated. Table 7.7 reports the results considering different layout of buildings:

- considering the actual situation;

- increasing the street width from 15 to $25 \mathrm{~m}$;

- limiting the maximum height of buildings to 12 and $6 \mathrm{~m}$;

- having a garden in front of the point of measurements instead of an apartment building.

Every simulation was repeated using the same values of environmental variables (air temperature and RH, wind velocity) as measured during the experimental sessions. Results in Table 7.7 show that an increase in Sky View Factor (SVF) thus allowing a more effective nightly cooling of surfaces and a decrease of $T_{m r}$. In particular, limiting the maximum height of buildings to $6 \mathrm{~m}$ would be the action with the most relevant effect. The mean radiant temperature was shown to decrease by $2.6{ }^{\circ} \mathrm{C}$ and PMV by 0.2 . Anyway, the night effects of an increased SVF were probably underestimated by RayMan, because the mean radiant temperature and so PMV and PET were calculated by knowledge of air temperature (input) that is 
Table 7.7 Calculated $T_{m r}$ and thermal comfort indexes in via Pindemonte (Bowen ratio $=1.5$, cloud cover $=1$ okta, clothing $=0.5$ clo, activity level $=80 \mathrm{~W}$ above the basal metabolism) for different disposition of buildings

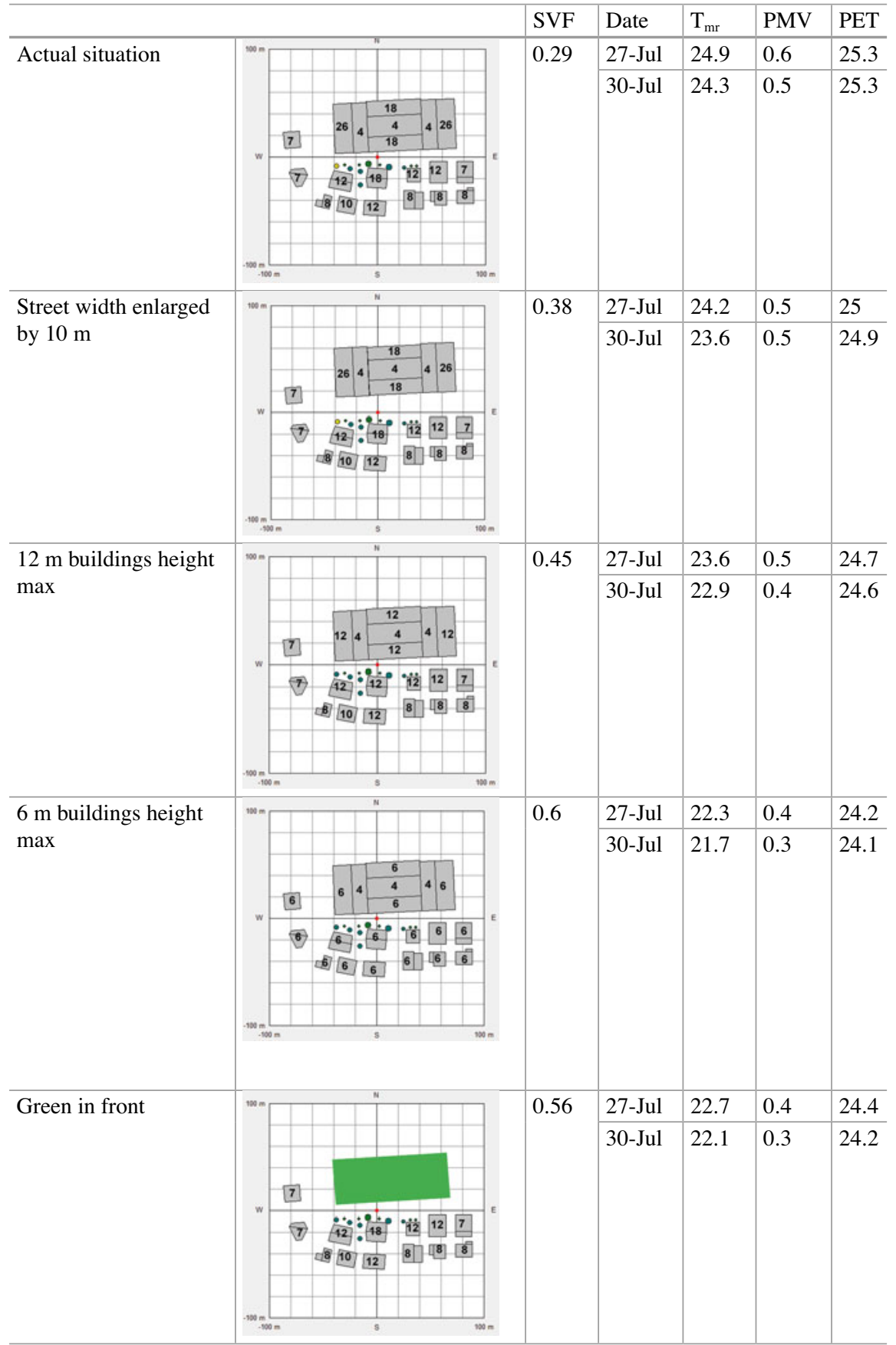


actually expected to decrease when SVF increases. Also the effect of having the green (last solution of Table 7.7) was probably underestimated because the model does not consider the cooling effect due to evapotranspiration.

The measures just described can be suggested both in new and built areas, in case of a redevelopment of an existing urban area. Within the frame of the European Project "UHI", the Authors conducted simulations using the ENVImet model (Bruse and Fleer 1998) in order to quantify the effect of selected mitigation actions (usable in already built areas) in the pilot are of via Pindemonte.

ENVI-met is a three-dimensional microclimate model designed to simulate the surface-plant-air interactions in urban environment with a typical resolution of $0.5-$ $10 \mathrm{~m}$ in space and $10 \mathrm{~s}$ in time. The model area is described in Fig. 7.4 and Fig. 7.5. The main area is a $99 \times 70 \times 30$ grid (in a x,y,z tridimensional reference system), with a $5 \times 5 \times 3 \mathrm{~m}$ grid dimension. An appropriate number of nesting grids (five) has been set in order to minimize boundary effects. Four specific points of interest have been identified in the zone to characterize the air temperature (at $2 \mathrm{~m}$ above ground) during $24 \mathrm{~h}$, from 6 am to $6 \mathrm{pm}$. Simulations lasted $72 \mathrm{~h}$, but only the last $24 \mathrm{~h}$ have been considered for the results. The daily mean air temperature of the days before the start simulation ones (Table 7.8) have been used as initial air temperature at 6 am of the first day. As requested by the Project, four characteristic days representative of the four seasons were considered. Simulations used the default values of ENVImet except for the ones reported in Table 7.8.

To measure the UHI intensity, simulations have been extended in the rural zone just outside Padua (Via Roma), in the same point where the previously described experimental measurements have been conducted during 2012 summer. Four scenarios were supposed besides the actual one ("AsIs" scenario):

- "Green ground": increasing the pervious surfaces of the area from $18 \%$ to $23 \%$ by planting trees, $10 \mathrm{~m}$ height, within the urban canyon and the main road of the area, and converting an impervious zone - eg asphalt car park surface - to a pervious zone by planting grass. The main effects were: Sky View Factor decreases for the presence of trees along the streets; impervious surface fraction decreases (and pervious surface fraction increases) because green area increases; albedo slightly increases; other thermo-physical properties of the surfaces/materials remain quite the same;

- "Cool pavements": substituting all the traditional asphalt (albedo 0.2) and concrete (albedo 0.4) (roads and pavements) with "cool materials", that is materials with an higher albedo (0.5). The main effects were that albedo significantly increases while other properties remain the same;

- "Cool roofs": using of "cool materials" for the horizontal impervious surfaces of roof. In particular albedo has been increased from 0.3 to 0.6 for roofs;

- "Green ground + cool pavements": scenario with both the mitigation actions just described simultaneously. 


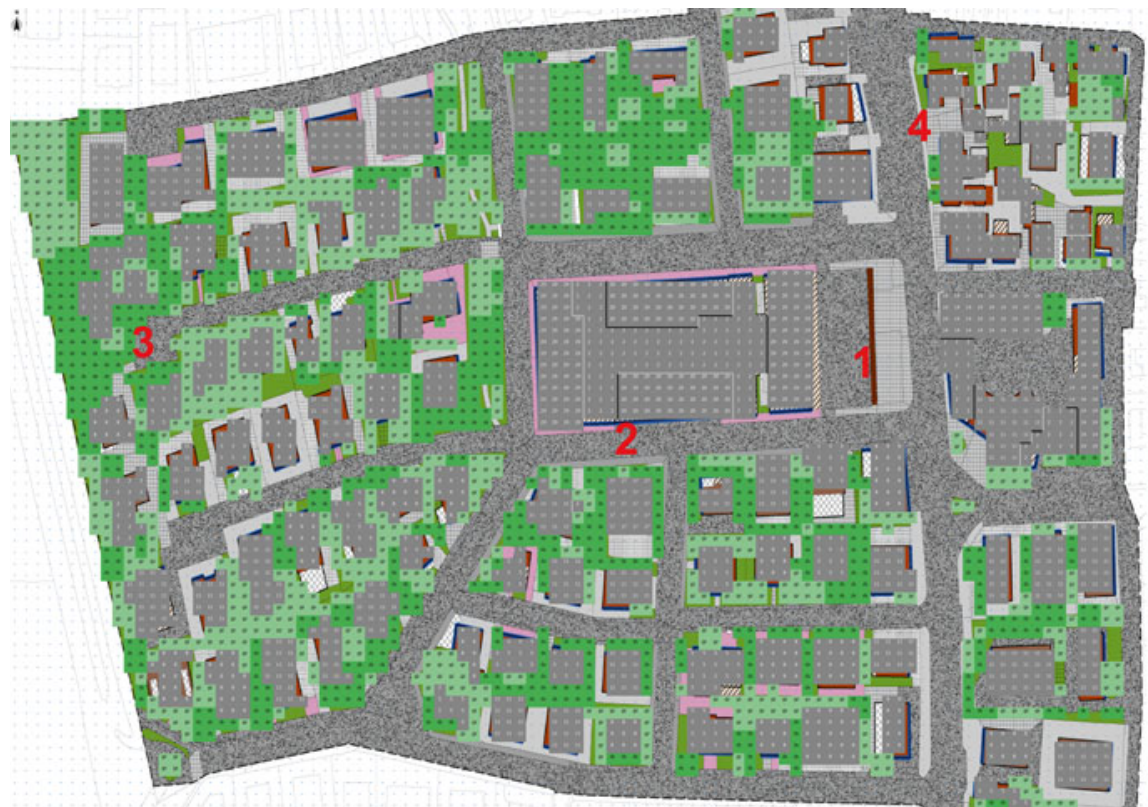

Fig. 7.4 The model area in ENVImet used for the simulations of the "AsIs", "Cool pavements" and "Cool roofs" scenarios. The red numbers identify four characteristic points for which air temperature at $2 \mathrm{~m}$ above ground has been considered in the study

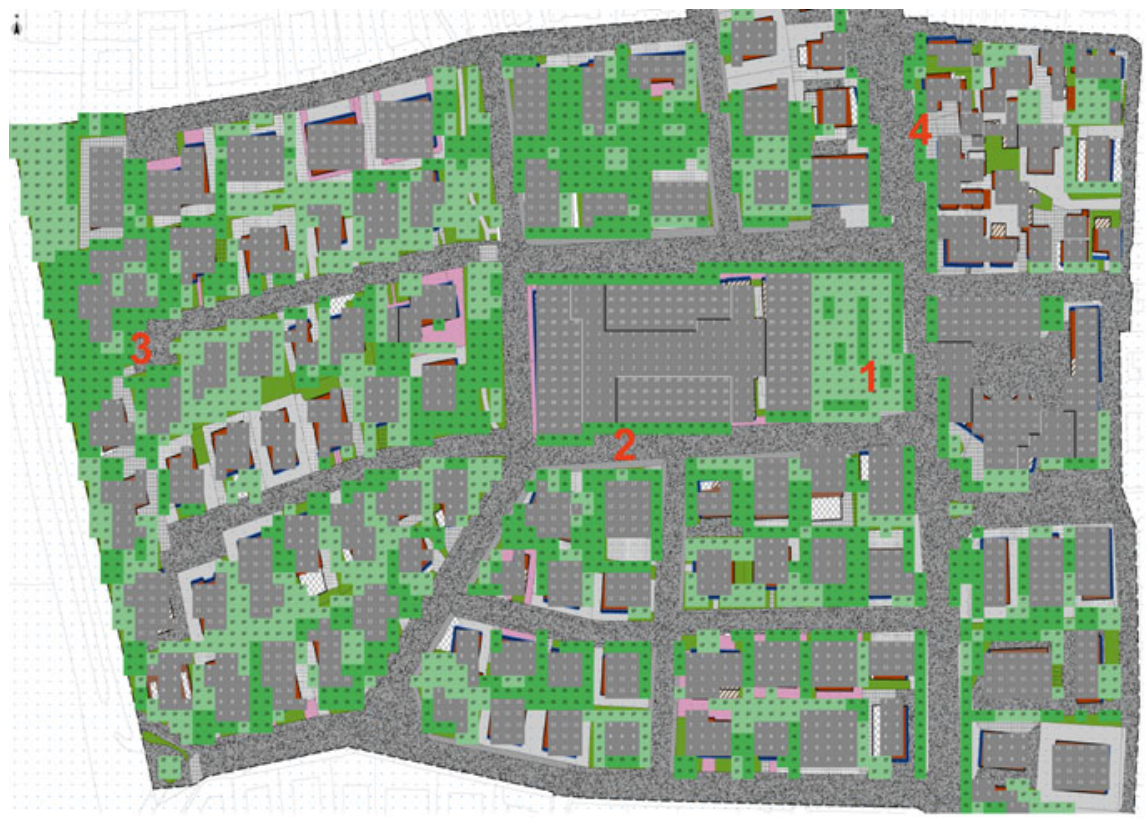

Fig. 7.5 The model area in ENVImet used for the simulations of the "Green ground" and "Green ground + Cool pavements" scenarios. The red numbers identify four characteristic points for which air temperature at $2 \mathrm{~m}$ above ground has been considered in the study 
Table 7.8 Configuration values in ENVImet

\begin{tabular}{|c|}
\hline Simulation tool: ENVI-met 3.1 \\
\hline Start Simulation at Day (DD.MM.YYYY): \\
\hline 02.02.2012 Winter; 02.05.2012 Spring; 27.07.2012 Summer; 03.11.2012 Autumn \\
\hline Start Simulation at Time (HH:MM:SS) $=06: 00: 00$ \\
\hline Total Simulation Time in Hours $=72.00$ \\
\hline Save Model State each $? \min =60$ \\
\hline Wind Speed at $10 \mathrm{~m}$ ab. ground $\left[\mathrm{m} \mathrm{s}^{-1}\right]=3$ \\
\hline Wind Direction (0:N.. 90:E.. 180:S.. 270:W..) $=90$ \\
\hline Roughness Length z0 at Reference Point $=0.1$ \\
\hline $\begin{array}{l}\text { Initial Temperature Atmosphere }[\mathrm{K}]=279 \mathrm{~K} \text { Winter; } 290.9 \mathrm{~K} \text { Spring; } 300 \mathrm{~K} \text { Summer; } 282.2 \mathrm{~K} \\
\text { Autumn }\end{array}$ \\
\hline Specific Humidity at $2500 \mathrm{~m}\left[\mathrm{~g}_{\text {water }} / \mathrm{kg}_{\text {air }}\right]=7$ \\
\hline Relative Humidity at $2 \mathrm{~m}[\%]=50$ \\
\hline Output: air temperature at $2 \mathrm{~m}$ above ground \\
\hline Building properties \\
\hline Inside Temperature $[\mathrm{K}]=298$ \\
\hline Heat Transmission Walls $\left[\mathrm{W} \mathrm{m}^{-2} \mathrm{~K}^{-1}\right]=1$ \\
\hline Heat Transmission Roofs $\left[\mathrm{W} \mathrm{m}^{-2} \mathrm{~K}^{-1}\right]=2$ \\
\hline Albedo Walls $=0.2$ \\
\hline Albedo Roofs =0.3 (all scenarios except "Cool roofs"); 0.6 (“Cool roofs") \\
\hline Albedo pavements =0.4 (all scenarios except "Cool pavements"); 0.5 (“Cool pavements") \\
\hline Albedo roads $=0.2$ (all scenarios except “Cool pavements”); 0.5 (“Cool pavements”) \\
\hline
\end{tabular}

Results, in terms of $24 \mathrm{~h}$ of air temperature at $2 \mathrm{~m}$ above ground and UHI intensity with respect to Via Roma (rural zone) are reported in Fig. 7.6 for the point 1 of Fig. 7.4 (as representative of the area) and for the four characteristic days of the year. Summarizing, the main results were:

- The higher UHI intensity (difference between the "AsIs" and "Via Roma" curves per each hour of the day) is obviously obtained in summer. During the other seasons the UHI phenomenon is much lower and negligible in winter during the central hours of the day;

- Talking about the summer, the higher UHI intensity $\left(9-10^{\circ} \mathrm{C}\right)$ is noticed after the sunset $(8 \mathrm{pm})$ and till the first sunrise $(4 \mathrm{am})$;

- The same value of $9-10{ }^{\circ} \mathrm{C}$ for the UHI intensity during the day is noticed only for point $2(1 \mathrm{pm})$, that is a street canyon (characterized by low SVF and impervious surfaces); for the other points the maximum daily UHI intensity is always lower than $9^{\circ} \mathrm{C}$;

- The best UHI mitigation strategy is the "Green ground+cool pavements" (Scenario 4) that allows $2{ }^{\circ} \mathrm{C}$ decrease in UHI maximum intensity (but till nearly $3{ }^{\circ} \mathrm{C}$ decrease in Point 2);

- The "Cool pavements" mitigation strategy allows between 1 and $2{ }^{\circ} \mathrm{C}$ decrease in UHI maximum intensity in all the points; 


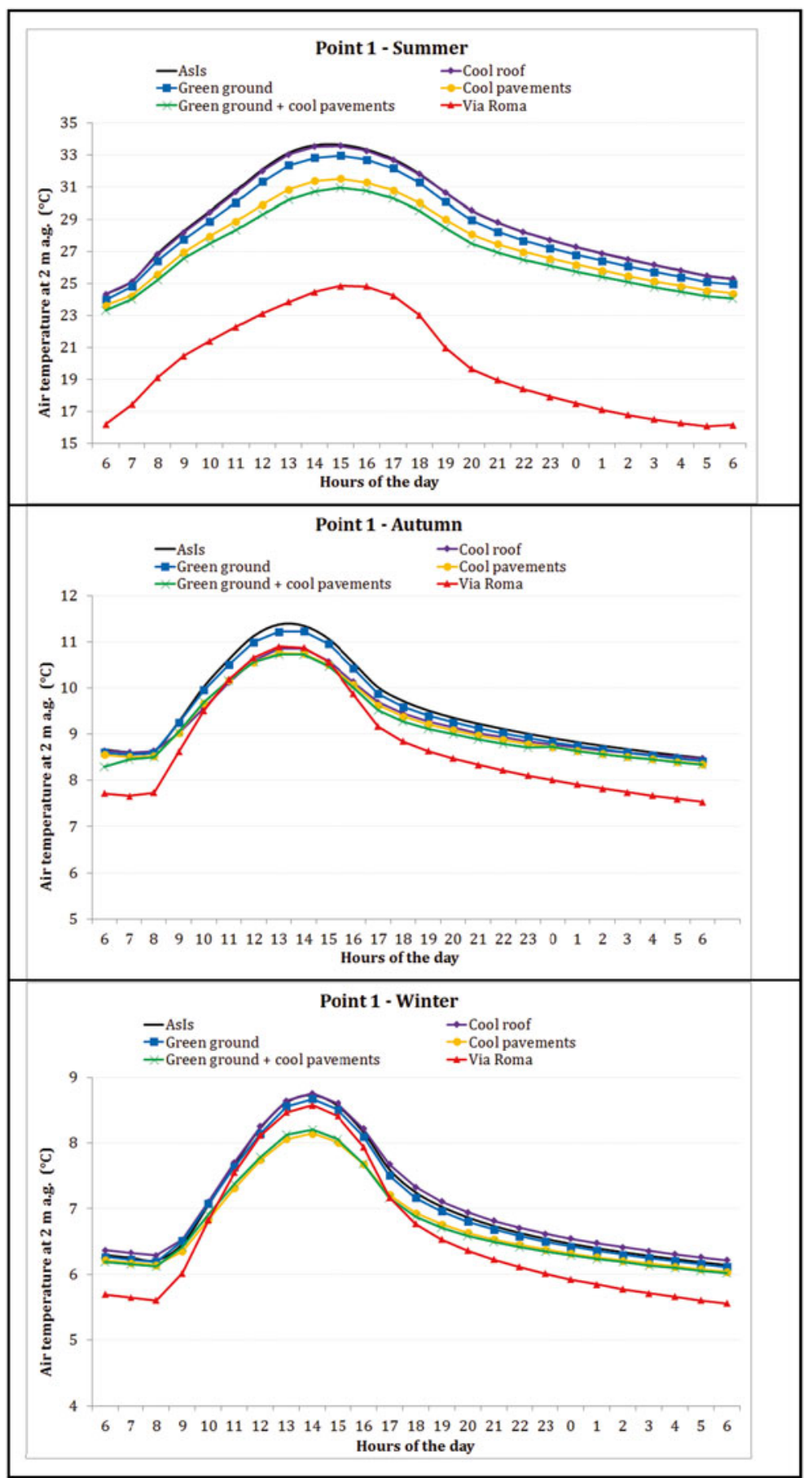

Fig. 7.6 Air temperature at $2 \mathrm{~m}$ above the ground during one typical day (from 6 am to 6 am of the day after) for each season at point 1 of the pilot area modelled by ENVImet (asphalt car park surface in front of a flat block). The differences between the upper curve (the actual scenario "AsIs") and the other ones depict the UHI intensity mitigation for the strategies described in the text 


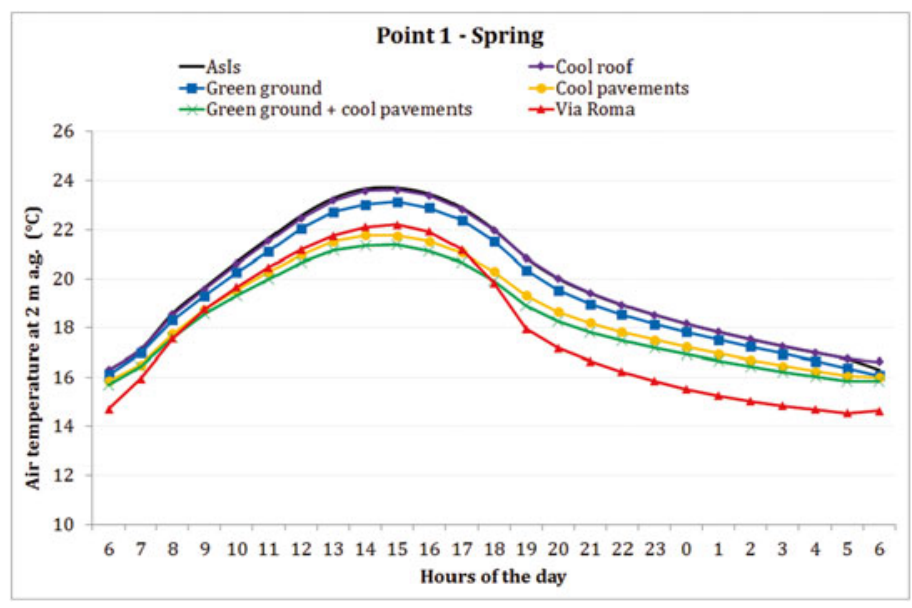

Fig. 7.6 (continued)

- The "Green ground" mitigation strategy allows an appreciable UHI maximum intensity decrease only in point 2 (around $1{ }^{\circ} \mathrm{C}$ ): in all other points the positive effect of the action is quite negligible;

- During the day (afternoon) the most effective mitigation actions are "Green ground" and "Green ground + cool pavements": they allow till $3{ }^{\circ} \mathrm{C}$ decrease in UHI intensity;

- During all the other seasons, but especially in winter, the most effective UHI mitigation strategies ("Cool pavements" and "Green ground + cool pavements") cause a negative effect during the central hours of the day: UHI intensity becomes negative, that is air temperature in urban zone id colder (about $0.5^{\circ} \mathrm{C}$ ) than in rural zone.

Acknowledgement This chapter was based on the work undertaken as part of the UHI Project implemented through the CENTRAL EUROPE Programme 2007-2013 co-financed by the ERDF (grant number 3CE292P3). The authors are grateful to Mr. Pierpaolo Campostrini and Mr. Matteo Morgantin (CORILA) for the support. Thanks to ARPAV and to Mr. Matteo Sottana for the use of meteorological data. Thanks to Prof. A. Matzarakis (Meteorological Institute - University of Freiburg) for the use of RayMan simulation model and to Prof. M. Bruse (Inst. of Geography University of Mainz) for the use of ENVI-met simulation model.

Open Access This chapter is distributed under the terms of the Creative Commons Attribution 4.0 International License (http://creativecommons.org/licenses/by/4.0/), which permits use, duplication, adaptation, distribution and reproduction in any medium or format, as long as you give appropriate credit to the original author(s) and the source, a link is provided to the Creative Commons license and any changes made are indicated.

The images or other third party material in this chapter are included in the work's Creative Commons license, unless indicated otherwise in the credit line; if such material is not included in the work's Creative Commons license and the respective action is not permitted by statutory regulation, users will need to obtain permission from the license holder to duplicate, adapt or reproduce the material. 


\section{References}

ARPAV Regional Agency for Environment Protection in Veneto (2011). Bilancio Energetico della Regione Veneto con dettagli provinciali sulla base dei dati disponibili fino all'anno 2010 (Veneto Region Energy balance with province details on the basis of data available till 2010). Technical Report.

Berkovic, S., Yezioro, A., \& Bitan, A. (2012). Study of thermal comfort in courtyards in a hot arid climate. Solar Energy, 86, 1173-1186.

Bruse, M., \& Fleer, H. (1998). Simulating surface-plant air interactions inside urban environments with a three dimensional numerical model. Environmental Modelling and Software, 13, 373-384.

Busato, F., Lazzarin, R., \& Noro, M. (2014). Three years of study of the Urban Heat Island in Padua: Experimental results. Sustainable Cities and Society, 10, 251-258, http://dx.doi. org/10.1016/j.scs.2013.05.001.

Gagge, A. P., Fobelets, A. P., \& Berglund, L. G. (1986). A standard predictive index of human response to the thermal environment. ASHRAE Transactions, 92, 709-731.

Honjo, T. (2009). Thermal comfort in outdoor environment. Global Environmental Research, 13, $43-47$.

Höppe, P. (1999). The physiological equivalent temperature-a universal index for the biometeorological assessment of the thermal environment. International Journal of Biometeorology, 43, $71-75$.

ISTAT Italian Statistical Institute (2012, July 30). Indicatori Ambientali Urbani (Urban Environmental Indexes). Technical Report. Available online, http://www.istat.it/it/ archivio/67990. Accessed 1 Mar 2013.

Jendritzky, G., \& Nubler, W. (1981). A model analysing the urban thermal environment in physiologically significant terms. Meteorology and Atmospheric Physics, 29, 313-326.

Matzarakis, A., Rutz, F., \& Mayer, H. (2007). Modelling radiation fluxes in simple and complex environments - application of the RayMan model. International Journal of Biometeorology, $51,323-334$.

Matzarakis, A., Rutz, F., \& Mayer, H. (2010). Modelling radiation fluxes in simple and complex environments - basics of the RayMan model. International Journal of Biometeorology, 54, 131-139.

Mayer, H. (1993). Urban bioclimatology. Experientia, 49, 957-963.

Mayer, H., \& Höppe, P. (1987). Thermal comfort of man in different urban environments. Theoretical and Applied Climatology, 38, 43-49.

Noro, M., Lazzarin, R., \& Busato, F. (2015). Urban heat island in Padua, Italy: Experimental and theoretical analysis. Indoor and Built Environment, 24(4), 514-533. doi:10.1177/14203 26X13517404.

Rizwan, A. M., Dennis, V. C. L., \& Liu, C. (2008). A review on the generation, determination and mitigation of urban heat island. Journal of Environmental Sciences, 20, 120-128.

Thorsson, S., Lindqvist, M., \& Lindqvist, S. (2004). Thermal bioclimatic conditions and patterns of behaviour in an urban park in Göteborg, Sweden. International Journal of Biometeorology, $48,149-156$. 